\title{
GESTÃO CURRICULAR NO ENSINO SUPERIOR: CONTEXTOS DE DESENVOLVIMENTO
}

\author{
Itamar Mendes da SILVA \\ Jorge Nassim Vieira NAJJAR ${ }^{\text {ii }}$ \\ Marcelo LIMA ${ }^{\text {iii }}$
}

\begin{abstract}
RESUMO
Este artigo tem como objetivo discutir a gestão de currículo no Ensino Superior, por meio da descrição e da análise dos processos coletivos, internos e sistemáticos de revisão de currículos empreendidos na Universidade Federal do Espírito Santo (Ufes). O desenvolvimento das reflexões requereu tomar como ponto de partida a Universidade, tendo em vista sua criação, seu conceito e suas perspectivas. Discutir o currículo em seus contextos, caminhos e descaminhos, em uma instituição universitária pública, localizada no menor e menos rico Estado do Sudeste, como é essa proposta, exigiu tecer considerações sobre: a) conceito, significado e possibilidades organizativas do Currículo no Ensino Superior e, especificamente, na universidade; b) caminhos e perspectivas da Ufes no processo de organização de currículo. Assim, as reflexões consideraram esses elementos e foram realizadas a partir do exame de documentos e do conteúdo de entrevista. $\mathrm{O}$ estudo possibilitou concluir que se faz necessário problematizar a pseudoneutralidade dos indicadores educacionais, sua capacidade de indução de práticas curriculares no Ensino Superior; problematizar a expropriação da autonomia curricular dos docentes e sua responsabilização pelos resultados educacionais; e, também, afirmar o caráter contraditório dos processos coletivos e colegiados de decisão curricular nas relações com os sujeitos individuais e coletivos responsáveis por conceber, elaborar, praticar e avaliar o currículo no Ensino Superior.
\end{abstract}

PALAVRAS-CHAVE: Gestão de currículo; Ensino Superior; Currículo; Avaliação.

\section{CURRICULUM MANAGEMENT IN HIGHER EDUCATION: DEVELOPMENT CONTEXTS}

\section{ABSTRACT}

This article aims to discuss curriculum management in Higher Education, describing and analyzing the collective, internal and systematic processes of curriculum revision in Higher Education concerning to the Federal University of Espirito Santo - (UFES), Brazil. The development of the reflections required us to take as a starting point the University, considering its creation, its concept and its perspectives. Discussing the curriculum in its contexts, paths and misleading paths in a public

\footnotetext{
${ }^{\text {i }}$ Doutor em Educação (Currículo) pela PUC/SP e pós-doutor em Políticas, Educação, Formação e Sociedade pela UFF. Professor Associado na UFES e diretor da Anpae-ES, gestão 2019-2021. Líder do Grupo de pesquisa Gestão, Trabalho e Avaliação Educacional - Getae (CNPq); integra o Grupo de Estudos e Pesquisas Paulo Freire - Geppf (CNPq) - e o Laboratório de Gestão da Educação Básica do Espírito Santo - Lagebes. Email: itamarmendes62@gmail.com.

ii Doutor em Educação pela Universidade de São Paulo. Professor Associado IV na UFF. Coordenador do Núcleo de Estudos e Pesquisas em Gestão e Políticas Públicas em Educação (NUGEPPE), da UFF; VicePresidente Sudeste da ANPAE; Tesoureiro da ANFOPE. Conselheiro Estadual de Educação e Membro do Fórum Estadual de Educação. E-mail: jorgenajjar@gmail.com.

iii Doutor em Educação e pós-doutor em historiografia da educação profissional pela UFF. Professor Associado na UFES, Membro do PPGE-UFES na linha de pesquisa Formação humana e políticas públicas, membro do Neddate, THESE e do "EM pesquisa". Vice-líder do grupo de pesquisa Gestão, Trabalho e Avaliação Educacional - Getae (CNPq). E-mail: marcelo.lima@ufes.br.
} 
university institution located in the smallest and the least rich southeast state, as we propose, required considerations of: a) concept, meaning and organizational possibilities of the curriculum in Higher Education, and specifically, at the University; b) the paths and perspectives of UFES in the curriculum organization process. Thereby, our reflections considered these elements and were made from the examination of documents and interview content. The study allowed us to conclude that it is necessary to problematize the pseudo-neutrality of educational indicators, their ability to induce curricular practices in Higher Education; to problematize the expropriation of teachers' curriculum autonomy and their accountability for educational outcomes; and also to affirm the contradictory character of the collective and collegiate processes of curricular decision in the relations with the individual and collective subjects responsible for conceiving, elaborating, practicing and evaluating curriculum in Higher Education.

KEYWORDS: Curriculum management; Higher Education; Curriculum; Evaluation.

\title{
GESTIÓN CURRICULAR EN LA EDUCACIÓN SUPERIOR: CONTEXTOS DE DESARROLLO
}

\begin{abstract}
RESUMEN
Este artículo tiene como objetivo discutir la gestión del currículo en la Educación Superior, por medio de la descripción y análisis de los procesos colectivos, internos y sistemáticos de revisión de currículos emprendidos en la Universidad Federal de Espírito Santo - Ufes, Brasil. El desarrollo de las reflexiones requirió como punto de partida la Universidad, teniendo en vista su creación, su concepto y sus perspectivas. Discutir el currículo en sus contextos, caminos y descaminos en una institución universitaria pública, localizada en el menor y menos rico Estado del Sudeste, como es esta propuesta, exigió tejer consideraciones sobre: a) concepto, significado y posibilidades organizativas del Currículo en la Educación Superior y, específicamente, en la universidad; b) caminos y perspectivas de la Ufes en el proceso de organización del currículo. Así, las reflexiones consideraron estos elementos y fueron realizadas a partir del examen de documentos y del contenido de entrevista. El estudio posibilitó concluir que es necesario problematizar la pseudo neutralidad de los indicadores educacionales, su capacidad de inducción de prácticas curriculares en la Educación Superior; problematizar la expropiación de la autonomía curricular de los docentes y su responsabilización por los resultados educacionales; $y$, también, afirmar el carácter contradictorio de los procesos colectivos y colegiados de decisión curricular en las relaciones con los sujetos individuales y colectivos responsables por concebir, elaborar, practicar y evaluar el currículo en la Educación Superior.
\end{abstract}

PALABRAS CLAVE: Gestión de Currículo; Educación Superior; Currículo; Evaluación.

\section{INTRODUÇÃO}

O debate em torno do currículo tem assumido destaque nos dias atuais, especialmente em virtude de posicionamentos acerca da qualidade da educação, dos conteúdos ministrados desde a Educação Básica até o Ensino Superior. Em tempos de franco acesso a conteúdo disponível nas redes sociais, muitas pessoas emitem opinião a respeito do papel da escola, suas vicissitudes e dificuldades, inclusive chegando a formular "soluções" simples para o 
trabalho complexo de educar. Dignam-se, inclusive, a prescrever "o que" e "o como" ensinar, evidenciando o campo do currículo como crescente espaço de disputa.

É possível afirmar que a colocação do currículo no centro dos debates, como "território em disputa" (ARROYO, 2013), é resultado do trabalho e da luta dos professores em defesa da educação cada vez mais democrática e emancipadora com qualidade socialmente referenciada em todos os níveis. Contudo, constatam-se, ainda, propostas questionadoras desse movimento e que se lançam sobre a autonomia docente e das instituições educativas na definição dos currículos.

Definindo os docentes como "doutrinadores esquerdistas", setores conservadores e reacionários propõem ações de controle da prática docente e do currículo. Por meio de projetos de lei, tenta-se abolir a liberdade de ensino com a proibição da discussão de temas como: gênero, sexualidade e até a teoria da evolução. Propõe-se uma suposta "escola sem partido", um “ensino sem ideologia” e a educação doméstica: homeschooling ${ }^{1}$.

Nesse contexto, é necessário reafirmar a educação como processo social de constituição do ser humano, de humanização, como direito de cidadania e dever do Estado e, assim, não é nem pode ser neutra (FREIRE, 1969). O currículo expressa, então, a organização desse processo e, assim como a cultura, é terreno de disputa, o que impossibilita assumir a cultura erudita como universal e unitária. Nele, promove-se a escolha e a decisão dos elementos culturais a serem ensinados. Essas escolhas encerram, contextualmente, relações de poder nas quais concorrem diferentes visões de mundo, de homem, de conhecimento, de educação, de escola, que se encontram em contínuo processo de constituição, de construção e de desenvolvimento, envolvendo desde os níveis centrais de definição de políticas curriculares (currículo prescrito) até o desenvolvimento do ensino-aprendizagem na sala de aula (currículo em ação) (FREIRE; MACEDO, 1994; SACRISTÁN, 2000). Como destacam Roldão e Almeida (2018), esse processo de gestão do currículo encerra decisões em três níveis: macro, meso e micro.

Nesse contexto, pretende-se influenciar os processos de decisão sobre o currículo desde a sua concepção e normatização geral até as práticas curriculares na escola. Exemplar é a reportagem publicada pela revista Veja para questionar o fazer da escola básica a partir de enquete feita com professores/as. Nela, criticam-se os professores, afirmando que estes "[...] idolatram personagens arcanos sem contribuição efetiva à civilização ocidental, como o 
educador Paulo Freire, autor de um método de doutrinação esquerdista disfarçado de alfabetização" (WEINBERG; PEREIRA, 2008).

Ao tentar desqualificar os professores pela adesão ao pensamento de Paulo Freire, Patrono da Educação Brasileira (Lei No 12.612/2012), atribuindo-lhes as responsabilidades pelos indicadores educacionais insatisfatórios, pretende alijá-los em suas prerrogativas de decisão curricular no âmbito meso e micro (instituição, grupos, projetos e sala de aula). Ainda, torná-los apenas executores, extraindo a natureza criativa e intelectual do trabalho docente (GIROUX, 1997). Nesse caso, o currículo adequado seria o decidido por especialistas externos à escola e capaz de responder positivamente aos testes de larga escala: Saeb, Enem, Enade, entre outros.

No Ensino Superior, especificamente, o foco nos exames, com forte apelo técnico e profissionalizante, tem produzido distorções no currículo ao restringi-lo da diversidade e do contexto e afastá-lo dos objetivos educacionais mais amplos de formação cidadã e de emancipação humana. Além disso, os "remédios" têm seguido, invariavelmente, uma mesma receita de buscar ampliar o controle sobre o fazer das instituições e dos docentes. Assim, para além dos exames, se tem buscado determinar o que se ensina e como se ensina pelo controle do produto. As ações decorrentes dessas práticas examinadoras e ranqueadoras vêm constrangendo o currículo e distorcendo o objetivo da educação ao restringir a autonomia dos docentes, tomados aqui como intelectuais organizadores do currículo em seu nível de atuação.

Essas práticas que impactam o currículo têm provocado nos meios acadêmicos calorosas discussões. Pensá-lo em seus contextos, caminhos e descaminhos, em uma instituição universitária pública, como é objetivo neste artigo, requer tecer considerações sobre: 1) conceito, significado e possibilidades organizativas do Currículo no Ensino Superior; 2) caminhos e perspectivas da Universidade Federal do Espírito Santo (Ufes), no processo de organização de currículo. A problematização de tais questões requer, ainda, analisar a (im)possível neutralidade da educação e a autonomia docente e da Universidade na composição do currículo, bem como discutir os processos institucionais de conceber, de elaborar, de praticar e de avaliar o currículo.

A perspectiva de buscar a compreensão do processo de gestão curricular na Ufes, entre os anos de 2008 e 2019, impôs à pesquisa, além de uma natureza qualitativa, a necessidade de se obter informações que ajudassem a compor os caminhos trilhados pela Instituição para chegar ao patamar atual. Tal período se justifica pela ação institucional de gestão curricular 
ter, em 2008, um momento de ampliação do investimento na orientação, na assessoria e no acompanhamento da elaboração/revisão de Projeto Pedagógico de Curso - PPC. Também em virtude de que os processos de avaliação externa começam a produzir impactos institucionais. Assim, mostraram-se relevantes os documentos produzidos ao longo do período, concebendoos a partir de Lüdke e André (1986, p. 38) como “[...] leis e regulamentos, normas, pareceres, cartas, memorandos, [...]". Ainda, entendem-se relevantes informações de gestores que puderam oferecer elementos tanto sobre o caminho e os processos de construção dos documentos propriamente ditos como sobre o funcionamento das decisões curriculares no âmbito institucional, do curso e do departamento acadêmico (meso) e da sala de aula (micro).

\section{UNIVERSIDADE: LOCUS DE FORMAÇÃO HUMANA, DE PRODUÇÃO E DE SOCIALIZAÇÃO DE CONHECIMENTO E DE FORMAÇÃO PROFISSIONAL}

A concepção de universidade depende da estrutura social e do poder político prevalente nos contextos históricos: “[...] não há um conceito único e universalmente válido de universidade, nem suas funções são as mesmas em tempo e em espaços diferentes" (BELLONI, 1992, p. 71).

Na Europa do século XI, Bolonha constituiu-se pioneira com a criação da Universitas Scholarium por uma corporação de estudantes. Pouco depois, foi criada, por um grupo de professores, na cidade de Paris, a Universitas Magistrorum. Entretanto, é importante destacar que o termo universitas foi utilizado à época para designar corporação profissional e não apenas de professores (CASTANHO, 2000, p. 20). Nesse sentido, essas iniciativas de estudantes ou de professores não poderão, ainda, ser caracterizadas como universidades, mas suas precursoras.

Afirmam Charles e Verger (1996, p. 7) que se se atribuir ao termo "[...] o sentido preciso de 'comunidade (mais ou menos) autônoma de mestres e alunos reunidos para assegurar o ensino de um determinado número de disciplinas em nível superior' parece claro que tal instituição é uma criação específica da civilização Ocidental [...]”, tendo Itália, França e Inglaterra do século XIII como seus locais de constituição.

No Brasil, a primeira universidade foi instalada no Rio de Janeiro em 1920 - atual Universidade Federal do Rio de Janeiro (UFRJ), apesar de inciativas anteriores não reconhecidas pelo poder central como a Universidade do Paraná, criada em 1912, pela iniciativa de particulares. (ROMANELLI, 1982). Somente no Estatuto das Universidades 
Brasileiras, Decreto № 19.851, de 11 de abril de 1931, autorizou-se aos Estados e à iniciativa privada a criação de universidades, conforme dispõe seu Artigo $6^{\circ}$ :

As universidades brasileiras poderão ser creadas e mantidas pela União, pelos Estados ou, sob a fórma de fundações ou de associações, por particulares, constituindo universidades federaes, estaduaes e livres.

Paragrapho unico. Os governos estaduaes poderão dotar as universidades por elles organizadas com patrimonio proprio, mas continuarão obrigados a fornecer-lhes os recursos financeiros que se tornarem necessarios a seu regular funcionamento (BRASIL, 1931, n.p.).

O Estatuto definiu também, em seu Artigo $1^{\circ}$, as finalidades do ensino universitário, o que ajudou a aproximar do modelo de universidade aqui implantado:

[...] elevar o nível da cultura geral; estimular a investigação scientifica em quaesquer domínios dos conhecimentos humanos; habilitar ao exercício de actividades que requerem preparo technico e scientifico superior; concorrer, emfim, pela educação do indivíduo e da collectividade [...] (BRASIL, 1931, n.p.).

Nos primeiros anos da vigência do Estatuto, tem-se verdadeiro boom de criação de universidades. Conforme informações do portal do Ministério da Educação ${ }^{2}$, pode-se concluir que foram criadas 16 instituições federais desde sua promulgação até a edição da LDBEN, em 1961. Também estados, notadamente os mais ricos, criaram suas instituições universitárias: em 1934, a criação da Universidade de São Paulo (USP) inaugurou esse processo que teve ainda a criação da Universidade Estadual do Rio de Janeiro (UERJ), em 1950; e a Universidade Estadual de Campinas (UNICAMP) em 1960. Entretanto, a maioria dos estados criou suas universidades a partir dos anos de 1970. Hoje, somente Sergipe, Espírito Santo, Rondônia e Acre não dispõem de universidades estaduais.

Foi também nesse período que foram fundadas as Pontifícias Universidades Católicas (PUCs), iniciando pelo Rio de Janeiro, em 1940; seguido por Campinas, em 1941; São Paulo, em 1946; Rio Grande do Sul, em 1948; Minas Gerais, em 1958; e Paraná, em 1959.

A organização das universidades criadas foi consolidada a partir de dois modelos gerais prevalentes: o francês (napoleônico) e o alemão (humbotdteano). O modelo francês, com um sentido de formação profissional ancorada na ciência, no desenvolvimento técnico e nos direitos humanos, que se caracteriza como ciência aplicada, ancora-se em valores políticos e sociais do estado e em suas necessidades de desenvolvimento econômico. $\mathrm{O}$ 
modelo alemão, elaborado por Alexander Von Humboldt, propõe uma universidade voltada à “[...] criação de um conhecimento novo" (TEIXEIRA, 1968, p. 22), de ciência básica.

No Brasil, identifica-se, então, a coexistência dos modelos com instituições que se notabilizam pelo desenvolvimento científico e pela geração de conhecimento novo, por meio da pesquisa básica ou aplicada, e instituições que se constituem mais como instituições de ensino e extensão. A Ufes coloca-se entre as primeiras, assim como a maioria das instituições públicas.

A LDBEN, Lei No 9.394/1996, assim define universidade:

Art. 52. As universidades são instituições pluridisciplinares de formação dos quadros profissionais de nível superior, de pesquisa, de extensão e de domínio e cultivo do saber humano, que se caracterizam por: I - produção intelectual institucionalizada mediante o estudo sistemático dos temas e problemas mais relevantes, tanto do ponto de vista científico e cultural, quanto regional e nacional; II - um terço do corpo docente, pelo menos, com titulação acadêmica de mestrado ou doutorado; III - um terço do corpo docente em regime de tempo integral (BRASIL, 1996, n.p.).

É nesse contexto de desenvolvimento do campo universitário no Brasil que se situa a Ufes, constituída em 1954 da união de cursos superiores particulares existentes na capital do Estado. A estatização das faculdades de Educação Física, Direito e Odontologia representam o passo inicial e núcleo fundacional da Universidade. Todavia, poucos anos depois, em 30 de janeiro de 1961, por ato do então presidente Juscelino Kubitschek, a "Universidade Estadual, um projeto ambicioso, mas de manutenção difícil, se transformava numa instituição federal” e passou a ser denominada Universidade Federal do Espírito Santo. Essas informações presentes no sítio da Ufes contradizem o Ministério da Educação (MEC) que apresenta, em seu portal, uma linha do tempo com a criação das Universidades Federais na qual indica a origem do projeto e, nesse quadro, a Ufes aparece como criada em 1961, sem qualquer referência à federalização da Universidade do Espírito Santo.

Atualmente, pode-se encontrar no portal da Ufes (www.ufes.br/história) a seguinte caracterização institucional:

Com quatro campi universitários - Goiabeiras e Maruípe, em Vitória; Alegre e São Mateus, no interior - a Ufes consolidou-se como referência em educação superior de qualidade, conceituada nacionalmente e fora do país. Nela estão cerca de 1.500 professores; 2 mil servidores técnicos; 19 mil alunos de graduação presencial, 1.200 de graduação a distância, e 3 mil de 
pós-graduação. Possui 102 cursos de graduação, 56 mestrados e 26 doutorados (UFES, 2019a, n.p.).

$\mathrm{Na}$ história da Ufes, apresentada no portal institucional, pretende-se destacar o papel social da instituição no contexto do Espírito Santo, pois, na criação de cursos e na distribuição dos campi, procura equilibrar a oferta no território do Estado, prioritariamente, de acordo com os arranjos produtivos locais (ex.: indústria e serviços na capital; agricultura no sul; agricultura e petróleo no norte). Afirma que a Ufes se tornou, ao longo de sua existência de 65 anos, em 2019, referência em formação em nível superior no Espírito Santo como única universidade pública. Nela, forma-se parte significativa, senão a maioria, dos atuais quadros profissionais, políticos e/ou religiosos do Estado.

É a partir da incorporação, em 1975, da "Escola Superior de Agronomia", localizada no município de Alegre, Sul do Estado (PEIXOTO; AGUIAR, 2006), e, depois, pelo processo de interiorização nos anos de 1980 e 1990, que se verifica a ampliação da oferta de vagas e a transformação da Ufes em Instituição de porte médio a partir dos anos 2000. São os contextos políticos, econômicos, sociais e as opções de governos que propiciam a construção da Ufes como instituição de dimensões médias com presença consolidada no cenário nacional e aspirações de internacionalização. Enfim, a instituição tem, hoje, valorizado índices, rankings como maneira de obter maior reconhecimento social ${ }^{3}$.

Apesar dos limites dos processos avaliativos com foco na performatividade, em que "[...] os desempenhos (de sujeitos individuais ou organizações) servem como medidas de produtividade e rendimento, ou mostras de 'qualidade' ou, ainda, 'momentos' de promoção ou inspeção" (BALL, 2002, p. 4), que visam, por um lado, ao monitoramento e ao controle; e, por outro lado, a construção de rankings, é importante reconhecer que estes se constituem, cada vez mais, em indicadores valorizados por amplos setores sociais. Como afirmam Calderón, Matias e Lourenço, “[...] é fato a expansão, em âmbito global, de rankings acadêmicos ou universitários que terminam por se tornar mecanismos indutores da concorrência entre IES, estabelecendo normas, indicadores e parâmetros referenciais do que seria a qualidade na educação superior" (2014, p. 228).

Ainda nesse sentido e contexto, colocam-se outros processos de avaliação realizados pelo MEC por meio do Instituto Nacional de Estudos e Pesquisas Educacionais Anísio Teixeira (Inep), nos quais a Ufes tem obtido conceito 4. No Ranking das Universidades Brasileiras (RUF) ${ }^{4}$, elaborado anualmente pelo jornal Folha de São Paulo desde 2012, a Ufes 
ocupava, em 2018, a posição de número 26, em um universo de 196 instituições. Desde que o jornal começou a publicar o RUF, a Ufes saiu de posição 60 para a posição atual. Corroborando Calderón, Matias e Lourenço (2014), pode-se afirmar que um dos elementos de contexto que fez a Instituição investir na revisão dos Projetos Pedagógicos de Curso (PPCs) e, especificamente, dos currículos neles contidos, foi a valorização desses índices.

\section{GESTÃO CURRICULAR: O PROJETO PEDAGÓGICO DE CURSO}

Os cursos de graduação têm processo de concepção, aprovação, implementação, avaliação e ajustes para se adequar ao seu tempo histórico e às necessidades formativas gerais (humanísticas e cidadãs) e da área específica a que pertence registrado no PPC. Ao proceder dessa forma, compõe-se o currículo do curso, que se caracteriza como conjunto de decisões e de ações organizadoras do ensino e da aprendizagem: “[...] implica não apenas o conteúdo programático [...], mas também, entre outros aspectos, os horários, a disciplina e as tarefas diárias que se exigem dos alunos [...]" (FREIRE; MACEDO, 1994, p. 70). Nesse mesmo sentido, Roldão e Almeida (2018, p. 20) afirmam que a organização “[...] do dia a dia da ação educativa concreta e as opções que os professores, em consonância com as decisões de cada equipa ou grupo, tomam individualmente na sala de aula [...]" compõem o nível micro de gestão do currículo com vistas a efetivar a aprendizagem com a qualidade desejada.

No PPC, materializam-se, ainda, as prescrições curriculares disponíveis em leis e normas que expressam tanto a normatividade geral da Constituição Federal, da LDBEN e das Diretrizes Curriculares Nacionais (DCN) quanto à normatividade específica da instituição universitária no uso de sua autonomia. Tais elementos expressam, respectivamente, os níveis macro e meso da gestão do currículo. Enquanto, no nível macro, está a chamada normatividade geral do sistema educacional; no nível meso, podem-se identificar dois momentos de elaboração e de tomada de decisão no processo coletivo de composição do currículo: a) o Institucional e, b) o do curso, que pode ser dividido em áreas e projetos inter ou transdisciplinares (ROLDÃO; ALMEIDA, 2018).

Nessa direção, a pesquisa identificou tendência da gestão central da Ufes em desenvolver ações para garantir a efetivação do currículo prescrito em nível macro e, para tanto, faz uso de: criação de disciplinas comuns para todos os cursos da universidade ou de uma determinada área (ex. Educação das Relações Étnico-raciais, LIBRAS, 
Empreendedorismo); criação de norma específica e para elaboração e revisão de PPC; criação de formulário eletrônico para a inserção de PPC no Sistema de Informação do Ensino (SIE); formação, assessoria e acompanhamento ao processo de gestão de currículo no nível institucional, dos cursos e de sala de aula.

A apropriação do conjunto normativo feita no interior de um curso com vistas a compor o currículo deve considerar, além do estatuto da área de conhecimento e de formação, o contexto de vida dos sujeitos e a realidade local a fim de que o currículo explicite sua relação com cultura da região, do país e com aspectos humanos universais, imprescindíveis para a formação cidadã. Assim, a organização do currículo, como processo de gestão, requer a participação dos envolvidos: professores, estudantes, gestores, técnicos administrativos e pessoal de apoio. Desse modo, a construção curricular deverá ser processo coletivo que observa "o princípio da gestão democrática" expresso no Artigo 56 da LDBEN e se produz a partir "de órgãos colegiados deliberativos, de que participarão os segmentos da comunidade institucional (BRASIL, 1996, n.p.).

Contudo, a participação coletiva na gestão do currículo não tem, ainda, tradição e história no Ensino Superior. Somente na Lei No 9.394/1996, pode-se identificar referência aos Currículos e aos Programas de Cursos como elemento e possibilidade da autonomia universitária:

Art. 53. No exercício de sua autonomia, são asseguradas às universidades, sem prejuízo de outras, as seguintes atribuições:

$[\ldots]$

II - fixar os currículos dos seus cursos e programas, observadas as diretrizes gerais pertinentes;

[...]

Parágrafo único. Para garantir a autonomia didático-científica das universidades, caberá aos seus colegiados de ensino e pesquisa decidir, dentro dos recursos orçamentários disponíveis, sobre:

I - criação, expansão, modificação e extinção de cursos;

II - ampliação e diminuição de vagas;

III - elaboração da programação dos cursos (BRASIL, 1996, n.p.).

Na LDBEN, tanto o inciso II do Artigo 53 quanto o Inciso III do Parágrafo Único consideram o PPC como responsabilidade da IES. Na Ufes, podem-se identificar variadas estruturas de PPC coexistindo ao longo do período estudado e não se encontrou norma institucional anterior a 2016 que organizasse a estrutura de PPC, o que pode indicar a descentralização de decisões quanto ao currículo e reforço de autonomia dos Colegiados de 
Curso. Entretanto, isso produziu um movimento dúbio de, por um lado, corroborar tradições democráticas e, por outro lado, permitir que vários cursos funcionassem por anos sem a estruturação explícita de um Projeto Pedagógico. Pois, em 2008, havia "11 cursos da Universidade, que não eram cursos novos, sem Projeto Pedagógico", dispondo apenas das matrizes disciplinares, afirmou, em entrevista para esta pesquisa, a diretora do Departamento de Desenvolvimento Pedagógico (DDP) da Pro-reitoria de Graduação (Prograd) no período entre 2008 e 2012.

A partir da edição da lei que institui o Sistema Nacional de Avaliação do Ensino Superior - Sinaes - (Lei No 10.861, de 14 de abril de 2004), a "elaboração da programação dos cursos" parece integrar movimento de busca de regularidades com a estrutura do PPC menos discrepante. Esse movimento não se detecta apenas na Ufes, pois, pretendendo atender a exigências da avaliação externa e conseguir boas notas para seus cursos, as IES ampliam normativas sobre os currículos e a construção do PPC. Para ratificar tal afirmação, basta uma rápida pesquisa em qualquer sítio de busca para se verificar a quantidade de normas e manuais produzidos por IES a partir daí. Também se constatará convergência normativa para as estruturas organizativas de PPC com vistas a contemplar os itens requeridos no instrumento de avaliação do Inep. É o papel indutivo da avaliação conformando o PPC e o currículo que o compõe.

A Comissão Própria de Avaliação (CPA) da Ufes parece atestar a indução da avaliação externa ao afirmar no Relatório de Avaliação Institucional (RAI), de 2016 que, em geral, o PPC se constitui elemento de fragilidade que ajuda a baixar a nota do curso nos processos de avaliação realizados pelo Inep. É possível depreender que a resposta à questão será dada pela Ufes por meio da Instrução Normativa (IN) $N^{0} 004 / 2016$, que institui e/ou reafirma entendimentos e consagra procedimentos ao normatizar a elaboração e a aprovação de PPC (UFES, 2016b). Nela, constata-se processo hierarquizado de análise e de aprovação de PPC envolvendo, em nível meso, câmaras e conselhos departamentais, departamentos acadêmicos e técnicos, Câmaras de Graduação Local e Central e homologação do Conselho de Ensino, Pesquisa e Extensão (Cepe). Assim, a aprovação do currículo de um curso expresso no PPC caracteriza-se como processo coletivo com a participação de representantes do conjunto dos sujeitos envolvidos e sua execução (currículo em ação) fica a cargo do 
colegiado do curso, composto por professores, estudantes, técnicos e, em alguns casos (Educação do Campo e Educação Indígena), inclui representantes de movimentos sociais.

Nesse sentido, as tradições democráticas da universidade brasileira, confirmadas pela LDBEN, são explicitadas nas ações da Ufes com vistas a atender as adequações e as sistematizações requeridas dos cursos no âmbito do Sinaes. Ainda, o período de implantação do Sinaes representou ponto de inflexão na gestão de currículo, pois se, em 2008, havia cursos que não dispunham de PPC estruturado, a partir da IN N ${ }^{0}$ 004/2016, passa-se a unificar suas estruturas e divulgação. A Universidade passa a estruturar e qualificar sua atuação na gestão dos currículos, reorganizando os PPCs para responder, em primeiro lugar, a imperativos normativos do sistema e, ao fazê-lo, promover centralização administrativa do processo. Corrobora essa conclusão a mudança de postura frente à "guarda" dos PPCs originais que deixam de ficar a cargo dos cursos com a assunção da responsabilidade pela gestão central da Universidade como afirmou a diretora do DDP, em entrevista para esta pesquisa: "A gente começou a trazer esse documento e manter arquivado na Prograd”.

A mudança de concepção e prática não se fez, porém, sem resistências e requereu empenho da gestão central, como apontou a diretora do DDP: "Houve vários momentos que tive que pedir ajuda ao reitor". A indicação é que as mudanças requerem investimentos de várias ordens, especialmente de cultura política institucional. A dificuldade inicial não foi apenas a incompreensão ou a resistência dos sujeitos envolvidos com os cursos diretamente (docentes, alunos e técnicos) nos locais de sua oferta, mas também pela dificuldade de se garantir investimento para a realização do trabalho. "Eram duas pessoas que tínhamos, no início, eram pessoas mais operacionais [...] não tinham essa visão de análise. Na medida em que depois concursos foram sendo feitos, que tivemos TAEs migrando para lá, pessoas de nível superior, as coisas foram melhorando".

Constata-se, nesse contexto, o desenvolvimento de um processo de avaliação dos cursos de graduação envolvendo discussão com os coordenadores, os professores e os alunos representantes dos colegiados de curso.

O Caderno de Avaliação dos Cursos de Graduação que ora lhes disponibilizamos reúne um conjunto de relatórios contendo indicadores sobre o ensino de graduação ao longo dos últimos anos. Estes relatórios foram produzidos a partir de diferentes fontes e dão visibilidade às informações que podem subsidiar o acompanhamento, a tomada de decisões 
e as ações de autoavaliação em desenvolvimento e/ou a serem implementadas no âmbito dos cursos (UFES, 2013a, p. 7).

O documento indica que a IES tomou providências para a avaliação e para a melhoria de seus cursos e da própria universidade. Entretanto, o que fica configurado é que o "passivo" era grande, os anos sem ações de gestão do currículo capazes de provocar uma sinergia na apropriação das normas gerais do sistema de Educação Superior (macro) entre os níveis meso (institucional, de curso/departamento/área) e micro (salas de aulas) parecem ter criado dificuldades para que a ação de avaliação surtisse o efeito desejado no tempo esperado.

Em 2013, a Ufes foi uma das primeiras Universidades públicas brasileiras que tiveram sanções aplicadas a cursos em virtude de resultados de avaliações. No total, foram seis cursos que, inicialmente, tiveram "medidas de regulação e supervisão" adotadas pelo então ministro da educação Aloizio Mercadante. No entanto, aos cursos de jornalismo e publicidade, foram aplicadas medidas mais drásticas com a suspensão do ingresso de novos alunos em virtude do fraco desempenho dos estudantes em dois ciclos avaliativos seguidos. Na Ufes, creditaram-se as notas baixas a suposto boicote dos discentes que, na prova do Enade, respondiam apenas ao questionário do estudante relatando graves problemas de infraestrutura no curso. Em um jornal da época, pode-se verificar o depoimento de um dos professores do curso que critica o boicote feito pelos alunos, mas, em sua análise, a responsabilidade deveria ser dividida com o MEC e com a Ufes por não terem realizado a avaliação do curso com um sentido de correção de rumos, antes da medida punitiva.

Amanheci com a notícia que o vestibular 2014 nos cursos de Jornalismo e Publicidade está suspenso pelo MEC, porque a avaliação do ENADE foi boicotada em 2009 e 2012. É claro que os estudantes devem refletir sobre esse ato e precisarem as suas responsabilidades sociais. Mas, nesses oito anos de Ufes, NUNCA o MEC avaliou nossas condições de infraestrutura, corpo docente e projeto político-pedagógico. Quer saber? Nem a UFES fez isso (MALINI, 2013, n.p.).

O boicote aos exames de estudantes de cursos de graduação aconteceu desde a instituição destes pela Lei $\mathrm{N}^{0}$ 9.131, de 24 de novembro de 1995, com o Exame Nacional de Cursos (ENC), mais conhecido como "Provão". A resistência ao Provão se constituiu ferramenta de luta ancorada na prerrogativa constitucional da autonomia universitária. $\mathrm{O}$ boicote foi perdendo força a partir das mudanças de conceito, sistemática e nome - Enade -, promovidas na avaliação pelo governo Lula que, em 2004, criou o Sinaes. 
Entre 2004 e 2012, não houve medidas punitivas tomadas em decorrência de processo avaliativo - Sinaes - que envolvessem Ifes. Todavia, em 2013, a crença de que a autonomia blindava a instituição e seus cursos frente aos processos de avaliação foi posta em xeque com ações envolvendo cinco Ifes, dentre as quais, a Ufes que teve dois cursos com o ingresso suspenso. Esse processo de suspensão de ingresso gerou uma resposta da Universidade que foi a assinatura de um Protocolo de Compromisso associado a um Termo de Cumprimento com previsão de melhorias quanto à infraestrutura e quanto ao PPC.

A partir de então, a instituição tomou medidas para sensibilizar a comunidade acadêmica para a avaliação interna e para participar das avaliações externas previstas no Sinaes. A avaliação assumiu destaque no interior da Ufes com a criação de uma Secretaria de Avaliação (Seavin), destinada a "[...] coordenar e articular as ações de avaliação desenvolvidas na instituição" (UFES, 2013b). Tais ações possibilitam identificar uma "cultura de avaliação" instalando-se e buscando consolidar a avaliação institucional que contou com ações esparsas na Ufes desde a década de 1990. É inegável que as ações regulatórias do MEC ajudaram a tornar a avaliação pedra de torque institucional com repercussões diretas nas políticas de gestão acadêmicas em geral e de currículo, especificamente, com criação de mecanismos de acompanhamento mais próximo do trabalho desenvolvido nos cursos.

O processo de gestão de currículo que centralizou a definição de itens e formatos da estrutura dos PPCs como também de alguns conteúdos a serem previstos para conjuntos expressivos de cursos produziu amplo movimento de revisão dos currículos. A constatação é de que os PPCs da maioria dos cursos de graduação necessitavam de ajustes e adequações ou porque vigoravam já a um período considerado longo ou por imposições de legislação expedidas em nível macro, prescrevendo alterações de currículo, como, por exemplo: licenciaturas, engenharias e medicina. No primeiro caso, tem-se a edição da Resolução $\mathrm{N}^{\circ} 2$, de $1^{\circ}$ de julho de 2015 (BRASIL, 2015a). No segundo caso, tem-se um conjunto de normas curriculares e lei que introduz a temática "combate a incêndio e prevenção de desastres" nos currículos dos cursos. Para a medicina, também havia novas leis a serem observadas, mas o mais importante era a publicação de nova diretriz curricular para o curso. Dessa forma, no período compreendido entre 2014 e 2018, constatam-se 110 processos de revisão e de reformulação de PPCs: 65 de bacharelados e 45 de licenciaturas.

É nesse contexto que o departamento responsável pelo desenvolvimento pedagógico o DDP - no nível da graduação, estabelece um regramento para a revisão e/ou a confecção de 
PPCs e faz publicar a IN N $\mathrm{N}^{\mathrm{O}}$ 004/2016. Esta é composta por cinco considerandos que a justificam e dois itens que estabelecem normas, apresentadas como anexo. Nela, confirma-se a avaliação de curso como indutora do currículo e de atualizações dos PPCs. Também se nota preocupação de explicitar a necessidade de coerência interna do planejamento institucional para a oferta dos cursos de graduação com a apresentação do PDI e do PPI como referências para a organização dos PPCs, conforme requer a lei do Sinaes.

No anexo da IN que se configura, de fato, como o locus da explicitação do teor da norma, identifica-se a preocupação com concepções mais gerais como de universidade, educação, currículo, metodologia, avaliação, extensão, pesquisa, além de indicar uma estrutura organizativa para o PPC com os itens obrigatórios, a saber: capa; sumário; identificação do curso; histórico da Ufes e do curso; concepção do curso que se divide em: a) contextualização, b) objetivos geral e específicos, c) metodologia, d) perfil do egresso; organização curricular que se divide em: a) concepção, b) estrutura curricular, onde se apresentam as disciplinas e sua natureza (obrigatória/optativa/integradora) e modalidade (presencial/semipresencial/a distância), as ementas e as bibliografias, o trabalho de Conclusão de Curso (TCC) e as atividades complementares; Pesquisa e Extensão no Curso; Autoavaliação do Curso; Acompanhamento e Apoio ao Estudante; Acompanhamento do Egresso; Regulamento de Estágio Obrigatório e Não Obrigatório; Regulamento para Atividades Complementares; Regulamento para Laboratórios de Formação Geral e Específica; Administração Acadêmica; Corpo Docente, que se divide em Perfil e Formação Continuada dos Docentes; Infraestrutura dividida em vários itens que abordam desde as instalações e equipamentos gerais do Campus até os existentes na sala de aula; Prática como Componente Curricular (específico para Licenciaturas); Observações. Para cada item exigido, há uma explicitação de concepção, significado e apresentação de "pistas" e informações de como obter e/ou compor os conteúdos do item específico.

O documento propõe-se a "[...] apresentar diretrizes para a elaboração e/ou atualização de Projeto Pedagógico de Curso (PPC) no âmbito da Universidade Federal do Espírito Santo (UFES)" (UFES, 2016, p. 1). Indica claramente o conjunto de documentos a serem compatibilizados e torna transparente seu caráter prescritivo/normativo em nível meso. Ainda, assume o regramento do Sinaes ao afirmar que: "Considera a cultura institucional da Ufes, suas normas internas e aquelas emanadas de instâncias e órgãos de normatização e regulação 
do sistema de ensino superior brasileiro" (UFES, 2016, p. 1). Por fim, afirma prestar-se para orientar “[...] o preenchimento de formulário eletrônico" (UFES, 2016, p. 1) indicado no qual o PPC é apresentado como "documento de identidade do Curso" que:

Define os princípios filosóficos, políticos, pedagógicos, administrativos e técnicos que orientam a formação humana/cidadã e profissional dos egressos do curso. Constitui-se em consonância com: Estatuto, Regimento, Projeto Pedagógico Institucional (PPI), Plano de Desenvolvimento Institucional (PDI) da Universidade, Projeto Político Pedagógico (PPP) e Regimento do respectivo Centro de Ensino e o conjunto de Diretrizes Curriculares Nacionais (DCN) atinentes a cada curso. Atende a Lei de Diretrizes e Bases da Educação Nacional (LDBEN) e ao que estabelece a Constituição Federal em seu Artigo $n^{\circ} 207$ e trata da indissocialização e da articulação entre "ensino, pesquisa e extensão" como imprescindíveis ao processo de formação profissional dos estudantes que deve ser realizado com flexibilidade curricular e articulação teoria e prática. O PPC é, então, como documento de identidade do curso, único e distinto, conforme legislação, com integralidade e terminalidade próprias (UFES, 2016, p. 1).

A julgar pela adesão da comunidade acadêmica ao processo de confecção dos PPCs, fica parecendo que a edição da norma foi adequada à realidade institucional. Ao se ler a IN, fica evidente a preocupação em se apresentar a regulamentação normativa e legal para os itens solicitados e também de se indicar onde os membros do colegiado de curso e do Núcleo Docente Estruturante (NDE) podem procurar as informações solicitadas. A IN é também um manual de elaboração de PPC.

A criação de normas internas à Universidade como forma de gerir currículo reformulando PPCs com vistas à melhoria da performance dos cursos em processos de avaliação externa parece ter surtido efeito na Instituição. A título de exemplo, observe-se texto publicado no portal da Universidade em 3 de abril de 2019, que comemora a nota máxima obtida por curso que teve seu PPC revisado no processo:

$\mathrm{Na}$ avaliação in loco anterior, realizada em 2015, a graduação em Estatística havia recebido nota 3, em uma escala de 1 a 5 . Desde então, passou por uma reestruturação e aprovou um novo Projeto Pedagógico de Curso (PPC), alinhado às diretrizes nacionais curriculares e às exigências da legislação (UFES, 2019b, n.p.).

A busca por acolher as regulamentações macro da gestão do currículo, seja do Conselho Nacional de Educação, do Ministério da Educação ou do Congresso Nacional, faz a Universidade ampliar o espectro de sua normatividade institucional com a criação de formulários obrigando departamentos acadêmicos (nível meso) a inserir e a disponibilizar os 
Programas das Disciplinas sob sua responsabilidade. Tal norma responde ao estabelecido no Artigo 47 da LDBEN, alterado pela Lei $\mathrm{N}^{\mathrm{o}}$ 13.168, de 6 de outubro de 2015, que, em seu parágrafo $1^{\circ}$, explicitou mais claramente a exigência de apresentar o Programa de Disciplina e Plano de Ensino aos discentes (BRASIL, 2015b). Nesse contexto, foi criado, em 2016, o formulário eletrônico específico na intranet para que os Departamentos Acadêmicos incluíssem os Programas das Disciplinas que ofertavam aos diversos cursos.

Concluída essa fase, passa-se a buscar padrões mínimos de uniformidade das ações de gestão de currículo em nível micro, a sala de aula. Apesar de essa seara ser tradicionalmente esfera do exercício da liberdade de ensino e da autonomia docente, sempre houve previsão regimental de aprovação do Plano de Ensino no departamento acadêmico do professor. Assim, a edição da norma e do formulário eletrônico para o Plano de Ensino causou surpresa aos docentes, mas foi acolhida devido à previsão normativa da Ufes e da LDBEN.

A edição da IN N ${ }^{0}$ 001, de 21 de fevereiro de 2017, coloca-se nesse contexto de exigência legal afirmando reconhecer a "[...] necessidade de critérios gerais para a elaboração de Plano de Ensino de disciplina ministrada em Curso de Graduação da UFES” (UFES, 2017, p. 1). Assim, o documento: "Normatiza as Diretrizes para Elaboração de Planos de Ensino no âmbito da Universidade Federal do Espírito Santo - UFES” " (UFES, 2017, p. 1), apresentando como fundamentos: o PDI e o PPI; Regimento Geral da UFES, em seus artigos 30 e 91; as exigências do Artigo 47 da LDBEN; a Lei $\mathrm{N}^{\mathrm{o}}$ 12.527, de 18 de novembro de 2011, que prevê o acesso à informação (BRASIL, 2011); a apontamentos e a indicações de avaliações realizadas pelo MEC/INEP.

A IN N $N^{0}$ 001/2017 apresenta um formulário anexo do qual constam, além da descrição dos aspectos mais formais como código, créditos, carga horária, os seguintes itens: Ementa; Objetivos específicos; Conteúdo programático; Metodologia; Critérios/Processo de avaliação da aprendizagem; Bibliografia básica; Bibliografia complementar; Cronograma (UFES, 2017). À exceção do item Ementa, para todos os outros, há no formulário instruções de preenchimento. A explicação obtida para isso é que a Ementa não pode ser alterada. Mais tarde, descobriu-se que também os objetivos e as referências bibliográficas não poderiam ser alterados, pois dependiam de alteração do PPC para tal. A implementação da medida contou com a inserção de formulário eletrônico no "Portal do Professor" com interface com o "Portal Acadêmico" e com o "Portal do Aluno". 
A interface com o "Portal do Aluno" constituiu-se em medida de Gestão de Currículo no âmbito institucional (meso) que disponibilizou aos estudantes as propostas de trabalho (Plano de Ensino) do professor com facilidade de acesso via internet em smartphones, tablets, computadores, com economia de materiais (papel, tinta) e de tempo e com facilidade para acessar a informação de qualquer lugar. A medida foi bem recebida pelos estudantes e pela administração da Ufes, pois, já em 2017, o contexto era de forte restrição orçamentária; assim, não se imprimir mais os planos de ensino era medida condizente com o momento.

É possível identificar crescimento na transparência das ações desenvolvidas pelos docentes com os estudantes, mas um subproduto desse processo é também, como aparenta, a ampliação do controle sobre o trabalho docente. Em se tratando de Plano de Ensino, está-se no campo específico de atuação docente, enquanto responsável por gerir o currículo no âmbito da sala de aula, e parece adequado pensar seu papel no processo.

Entende-se que as prescrições curriculares reservam ao docente papel fundamental que supera de maneira importante o ministrar aula: um papel de protagonista curricular. Entretanto, a indução da avaliação do desempenho no âmbito do Sinaes, que prevê Enade, avaliação de cursos, parece desencadear processo de restrição de autonomia em cascata: a instituição passa a ter de atender a critérios mais rígidos de desempenho em avaliações e reparte a restrição de autonomia com o docente, aumentando o controle sobre seu trabalho e diminuindo o espaço de atuação de intelectual capaz de selecionar, de organizar, de compor, de executar e de avaliar o currículo.

\section{CONCLUSÕES}

Neste texto, buscou-se apresentar e discutir o processo de gestão curricular no Ensino Superior descrevendo e analisando os processos coletivos, internos e sistemáticos de composição e revisão de currículos no âmbito dos PPCs (nível meso) e dos Planos de Ensino (nível micro) na Ufes,. $\mathrm{Na}$ análise, destacaram-se: a) a relação entre centralização e descentralização da gestão curricular; b) a avaliação externa na indução de mudanças na gestão curricular nos níveis meso e micro; c) o aprofundamento da transparência, mas também do controle do trabalho da IES, de seus processos de gestão curricular e do trabalho docente.

A reflexão fez-se acreditando na necessidade de se problematizar a pseudoneutralidade dos indicadores educacionais, a dubiedade das ações em torno da ampliação da transparência 
do trabalho pedagógico, a responsabilização dos docentes pelos resultados educacionais, bem como a autonomia institucional e docente como gestores do currículo. Considera-se que essas e outras medidas impactam diretamente o currículo e têm provocado nos meios acadêmicos calorosas discussões sobre essas e outras questões.

No decorrer da análise dos documentos e das informações coletadas, foi se evidenciando um desafio que percorreu todo o processo de trabalho: construir um percurso analítico objetivo. Analisar, pois, o percurso da gestão de currículo de uma Ifes, no contexto atual de ataque coordenado pelo ministro da Educação é desafio de grande monta, uma vez que pode induzir a duas posições igualmente perigosas: a) de um lado, assumir a defesa da universidade e não lograr êxito em fazer ciência; b) de outro, colocar-se em uma posição de crítica pretensamente neutra em nome da ciência. Nas duas posições, acaba-se por não se realizar uma análise da totalidade do fenômeno em contexto de desenvolvimento explicitando suas contradições com a mesma força argumentativa com que trata de suas superações e possibilidades de mudança e de melhoria institucional. Espera-se ter conseguido dar conta de superar os percalços e as armadilhas da situação e que este texto possa ser considerado como contribuição ao debate acerca da gestão de currículo do Ensino Superior no contexto de universidades públicas federais.

Pode-se afirmar que os investimentos nesta pesquisa levaram a colocar em evidência e a explicitar as contradições da regulação oficial nos processos de centralização das decisões curriculares no interior da Universidade com os princípios democráticos que regem o Ensino Superior no Brasil. Regulação que se faz associada ao controle da observância de instruções, de normas e de leis expedidas pelos órgãos do sistema, e tem no processo de avaliação das IES sua pedra de torque. Desse processo, pode-se dizer que, enquanto favoreceu a ampliação da transparência das informações curriculares em vários níveis, contraditoriamente promoveu a diminuição da autonomia para decisão sobre o currículo aos professores e colegiados de cursos e departamentais. Constatou-se, no caso em análise, que foi a partir da avaliação externa e de suas repercussões e acolhimentos internos que se criaram condições para certa padronização da estrutura curricular no âmbito dos PPCs e dos planos de ensino.

Por fim, é possível afirmar que os dilemas e as contradições do processo indicam movimento institucional na busca de superar limites e de construir horizontes de constantes investimentos em melhorias para o ensino, para a pesquisa, para a extensão e para a prestação 
de serviços à sociedade. Ainda, os dados evidenciam esforço institucional em todos os seus fóruns e níveis internos de gestão curricular para atender às demandas do sistema, especialmente àqueles aspectos que corroboram a construção de uma Educação Superior universitária pública, laica, inclusiva e de qualidade, socialmente referenciada. O caminho ainda é longo, contraditório e a tarefa, árdua.

\section{REFERÊNCIAS}

ARROYO, Miguel. Currículo, território em disputa. 5. ed. Petrópolis, RJ: Vozes, 2013.

BALL, Stephen. J. Reformar escolas/reformar professores e os terrores da performatividade. Revista Portuguesa de Educação, Braga, v. 2, n. 15, p. 3-23, 2002.

BELLONI, Isaura. Função da Universidade: notas para reflexão. In: BRANDÃO, Zaia et al. Universidade e educação. Campinas: Papirus; São Paulo: Cedes, 1992. p. 71-78.

BRASIL. Decreto $\mathbf{N}^{\mathbf{1}}$ 19.851, de 11 de abril de 1931. Dispõe que, o ensino superior no Brasil obedecerá, de preferência, ao sistema universitário... Brasília: Presidência da República, Secretaria-Geral, Subchefia para Assuntos Jurídicos, [1931]. Disponível em: http://www.planalto.gov.br/ccivil_03/decreto/1930-1949/D19851.htm. Acesso em: 8 mar. 2018.

BRASIL. Lei $\mathbf{N}^{\circ}$ 9.131, de 24 de novembro de 1995. Altera dispositivos da Lei $\mathrm{n}^{\circ} 4.024$, de 20 de dezembro de 1961, e dá outras providências. Brasília: Presidência da República, Secretaria-Geral, Subchefia para Assuntos Jurídicos, [1995]. Disponível em: http://www.planalto.gov.br/ccivil_03/leis/L9131.htm. Acesso em: 8 mar. 2018.

BRASIL. Lei $\mathbf{N}^{\circ}$ 9.394, de 20 de dezembro de 1996. Estabelece as diretrizes e bases da educação nacional. Brasília: Presidência da República, Casa Civil, Subchefia para Assuntos Jurídicos, [1996]. Disponível em: http://www.planalto.gov.br/ccivil_03/leis/19394.htm. Acesso em: 8 mar. 2018.

BRASIL. Lei $\mathbf{N}^{\mathbf{0}} \mathbf{1 0 . 8 6 1}$, de 14 de abril de 2004. Institui o Sistema Nacional da Avaliação Superior - SINAES e dá outras providências. Brasília: Presidência da República, Secretaria-Geral, Subchefia para Assuntos Jurídicos, [2004]. Disponível em: http://www.planalto.gov.br/ccivil_03/_ato2004-2006/2004/lei/110.861.htm. Acesso em: 8 mar. 2018.

BRASIL. Lei $\mathbf{N}^{\mathbf{0}}$ 12.527. de 18 de novembro de 2011. Regula o acesso a informações previsto no inciso XXXIII do art. $5^{\circ}$, no inciso II do $\S 3^{\circ}$ do art. 37 e no $\S 2^{\circ}$ do art. 216 da Constituição Federal... Brasília: Presidência da República, Casa Civil, Subchefia para Assuntos Jurídicos, [2011]. Disponível em: http://www.planalto.gov.br/ccivil_03/_ato20112014/2011/lei/112527.htm. Acesso em: 8 mar. 2018. 
BRASIL. Lei $\mathbf{N}^{\mathbf{0}} \mathbf{1 3 . 1 6 8}$, de 6 de outubro de 2015. Altera a redação do $\S 1^{\mathbf{o}}$ do art. 47 da Lei n 9.394, de 20 de dezembro de 1996 - Lei de Diretrizes e Bases da Educação Nacional. Brasília: Presidência da República, Secretaria-Geral, Subchefia para Assuntos Jurídicos, [2015b]. Disponível em: http://www.planalto.gov.br/ccivil_03/Ato20152018/2015/Lei/L13168.htm. Acesso em: 8 mar. 2018.

BRASIL. Lei $\mathbf{N}^{\mathbf{0}}$ 12.612, 13 de abril de 2012. Declara o educador Paulo Freire Patrono da Educação Brasileira. Brasília: Presidência da República, Casa Civil, Subchefia para Assuntos Jurídicos, [2012]. Disponível em: http://www.planalto.gov.br/ccivil_03/_Ato20112014/2012/Lei/L12612.htm. Acesso em: 8 mar. 2018.

BRASIL. Resolução CNE/CP N ${ }^{\circ}$ 2, de 1 de julho de 2015. Define as Diretrizes Curriculares Nacionais para a formação inicial em nível superior (cursos de licenciatura, cursos de formação pedagógica para graduados e cursos de segunda licenciatura) e para a formação continuada. Diário Oficial da União: seção 1, Brasília, DF, n. 124, p. 8-12, 2 jul. 2015 a. CALDERÓN, Adolfo Ignácio; MATIAS, Raone; LOURENÇO, Henrique. Rankings na Educação Superior: as Melhores Faculdades do Brasil (1982-2000). Estudos em Avaliação Educacional, São Paulo, v. 25, n. 57, p. 226-247, jan./abr. 2014.

CASTANHO, Sergio. A Universidade entre o sim, o não e o talvez. In: VEIGA, Ilma Passos; CASTANHO, Maria Eugênia (Orgs.) Pedagogia Universitária: a aula em foco. Campinas: Papirus, 2000. p. 13-48.

CHARLES, Christophe; VERGER, Jacques. História das Universidades. São Paulo: Unesp, 1996.

FREIRE, Paulo. Papel da Educação na Humanização. Revista Paz e Terra, [s.1.], n. 9, p. 123-132, out. 1969. Disponível em:

http://www.acervo.paulofreire.org:8080/jspui/bitstream/7891/1127/1/FPF_OPF_01_0003.pdf Acesso em: 7 mar. 2017.

FREIRE, Paulo; MACEDO, Donaldo. Alfabetização: leitura do mundo leitura da palavra. 2. ed. Rio de Janeiro: Paz e Terra, 1994.

GIROUX, Henry. Os Professores como intelectuais. Porto Alegre: Artmed, 1997.

LÜDKE, Menga; ANDRÉ, Marli E. D. A. Pesquisa em educação: abordagens qualitativas. São Paulo: EPU, 1986.

MALINI, Fábio. Ufes tem vestibulares de Jornalismo e Publicidade suspensos pelo MEC. D1 Notícias, Vitória, 6 dez. 2013. Disponível em:

http://www.d1noticias.com.br/exibe_noticia/index/5520?usuario=any. Acesso em 13 jun. 2018.

PEIXOTO, Maria do Carmo de Lacerda; AGUIAR, Rafael Educação Superior no Estado do Espírito Santo 1991-2004. In: RISTOFF, Dilvo; GIOLO, Jaime (Orgs.). Educação superior brasileira, 1991-2004: Espírito Santo. Brasília, DF: INEP, 2006. p. 21-65. 
ROLDÃO, Maria do Céu; ALMEIDA, Silvia de. Gestão Curricular: para a autonomia das escolas e professores. Lisboa: Ministério da Educação, Direção-Geral da Educação, 2018.

ROMANELLI, Otaíza de Oliveira. História da educação no Brasil (1930/1973). 3. ed. Petrópolis: Vozes, 1982.

SACRISTÁN, José Gimeno. O Currículo: uma reflexão sobre a prática. Porto Alegre: Artmed, 2000.

TEIXEIRA, Anísio. Uma perspectiva de Educação Superior no Brasil. Revista Brasileira de Estudos Pedagógicos, Rio de Janeiro, v. 50, n. 111, p. 21-82, jul./set. 1968.

UFES. Universidade Federal do Espírito Santo. Diretrizes para Elaboração de Projeto Pedagógico de Curso - PPC (Versão Preliminar). 2016a. Disponível em: http://prograd.ufes.br/sites/prograd.ufes.br/files/field/anexo/diretrizes_ppc_-_04-10-2016.pdf. Acesso em: 6 fev. 2020.

UFES. Universidade Federal do Espírito Santo. Instrução Normativa No 001/2017. Normatiza as Diretrizes para Elaboração de Planos de Ensino no âmbito da Universidade Federal do Espírito Santo - UFES. Vitória: Pró-Reitoria de Graduação, Departamento de Desenvolvimento Pedagógico, [2017]. Disponível em: http://prograd.ufes.br/sites/prograd.ufes.br/files/field/anexo/instrucao_normativa_prograd_00 1-2017.pdf. Acesso em: 6 fev. 2020.

UFES. Universidade Federal do Espírito Santo. Instrução Normativa No 004/2016. Normatiza as Diretrizes para Elaboração de Projetos Pedagógicos de Curso - PPC - no âmbito da Universidade Federal do Espírito Santo - UFES. Vitória: Pró-Reitoria de Graduação, Departamento de Desenvolvimento Pedagógico, [2016b]. Disponível em: http://prograd.ufes.br/sites/prograd.ufes.br/files/field/anexo/instrucao_normativa_0042016.pdf. Acesso em: 6 fev. 2020.

UFES. Universidade Federal do Espírito Santo. Caderno de Avaliação. Vitória: Pró-reitoria de Graduação, 2013a. Disponível em:

http://www.graduacao.ufes.br/sites/graduacao.ufes.br/files/field/anexo/comunica\%C3\%A7\% C3\%A30_social_jornalismo.pdf. Acesso em: 13 mar. 2018.

UFES. Universidade Federal do Espírito Santo. Secretaria de Avaliação Institucional Seavin. Vitória, 2013b. Disponível em: http://www.ufes.br/secretaria-deavalia\%C3\%A7\%C3\%A3o-institucional-seavin. Acesso em: 13 jun. 2018.

UFES. Universidade Federal do Espírito Santo. História. 2019a. Disponível em: http://www.ufes.br/hist\%C3\%B3ria. Acesso em: 6 fev. 2020.

UFES. Universidade Federal do Espírito Santo. Curso de Estatística obtém nota máxima do MEC e se torna um dos mais bem avaliados do Brasil. UFES, 3 abr. 2019b. Disponível em: 
http://www.ufes.br/conteudo/curso-de-estatistica-obtem-nota-maxima-do-mec-e-se-torna-umdos-mais-bem-avaliados-do. Acesso em: 6 fev.2020.

WEINBERG, Mônica; PEREIRA, Camila. Você sabe o que estão ensinando a ele? Revista Veja, 20 de agosto de 2008 - Edição 2074. p. 72-84.

\section{NOTAS}

${ }^{1}$ No município de Vitória, foi aprovado projeto de lei que autoriza a educação domiciliar. Disponível em: https://www.gazetadopovo.com.br/educacao/camara-dos-vereadores-de-vitoria-regulamenta-homeschooling/

${ }^{2}$ Disponível em: http://portal.mec.gov.br/sesu/arquivos/pdf/linhatempo-ifes.pdf. Acesso em: 16 jul. 2019.

3 Disponível em: http://www.ufes.br/conteudo/ufes-esta-entre-universidades-brasileiras-que-entraram-noranking-das-melhores-do-mundo. Acesso em: 16 jul. 2019.

${ }^{4}$ Disponível em: http://ruf.folha.uol.com.br/2018/ranking-de-universidades/. Acesso em: 16 jul. 2019.

Enviado em: 01/10/2019

Aprovado em: 28/01/2020 